\title{
Breeding of fungal resistant varieties derived from Grüner Veltliner by chromosomal selection
}

\author{
Ferdinand Regner, Robert Hack, Stefan Nauer, and Barbara Zöch \\ Höhere Bundeslehranstalt und Bundesamt für Wein- und Obstbau Klosterneuburg Wiener Straße 74, A-3400 Klosterneuburg, Austria
}

\begin{abstract}
Traditional cultivar Grüner Veltliner is the most appreciated vine in Austrian viticulture. Due to organic growing the demand for mildew resistance within the same wine profile has increased. Cross breeding can provide such new genotypes which combine traits from different sources by parenthood. Linkage of traits with chromosomes or markers allows to predict some aspects of the phenotype. Equipped with chromosomal assisted selection the development of new varieties could be much easier and faster. On the base of two segregating populations derived from crosses of Grüner Veltliner with Malverina and Seyval blanc we could define correlation of chromosomes with some traits. Mainly ampelographic descriptors and resistance against mildew could be aligned. As a quality parameter of the wine Rotundone analyses were performed and could be attributed to chromosome 5 and 9 . Selection supported by the composition of the parental chromosomes enables breeding with some arguments of design. The limits for free choice were the availability of sufficient different genotypes with a broad spectrum of chromosomal combinations. Recently released descendent cultivar Donauveltliner was selected due to the high rate of Traminer alleles.
\end{abstract}

\section{Introduction}

Grapevine cross breeding is again a task to improve the stability of growing vines under changed plant protection regimes [1]. In the meanwhile more than $10 \%$ of the Austrian viticulture are treated with organic methods [2] and as a consequence new varieties are required. Established traditional varieties lack substantial resistance against mildew diseases, which in organic production increases the risk of failing due to disease outbreak. New genotypes with improved resistance against most diseases should allow reduction of plant protection measurements [3]. Traditional varieties as the local most common Grüner Veltliner $(\mathrm{GV})$ are very sensitive to Powdery as well as Downy Mildew [4]. Hence a specific task is to create an offspring of Grüner Veltliner that combines the estimated wine profile with some resistance genes derived from other Vitis species [5]. Seyval blanc, Villard blanc, or in our case, Malverina could function as resistance donors and they were applied as crossing partners [6]. These donor vines show satisfying stability in the field but still lack adequate wine quality. Cross breeding and selection is a very laborious and time consuming task therefore it is useful to have tools for accelerating the whole process. Genetic markers are one of the essential prerequisites to improve and fasten selection [1]. While AFLP and SNP markers are more abundant in the genome [7] SSR markers are the better choice to anchor an allele [8]. Simple sequence repeat (SSR) markers are more stable than others, they are inherited codominantly and a huge amount of them is already attributed to a chromosome within a linkage group $[9,10]$. Some of them were already used successfully for marker assisted selection in the grapevine breeding process. Few of them are linked to resistance traits as the SSR marker VVIV67, which is located close to
Ren3 [11]. This marker allows a preselection for resistance against powdery mildew in an early stage of development. Others are also in connection with quality factors as the markers linked to terpene synthesis [12]. A rare terpene is Rotundone [13], one of the key aroma substances within Grüner Veltliner wines [14]. It is associated with a peppery, spicy taste that is the expected sensorial profile for several appellation wines in Austria.

Finally, segregation of chromosomes could easily be followed by genotyping the seedlings with stable SSRs. The segregation pattern of a specific SSR marker within a population allows to conclude which of the parental chromosomes were transferred to the off spring [8]. For mapping it would be necessary to involve large populations before any selection is done. Numerous markers have to be screened to get the mapping structure [15]. As an alternative strategy selection with chromosomal observation and definition of heritage was used to accelerate the breeding process.

\section{Material and methods}

Two populations of Grüner Veltliner were involved in the genetic analysis. The offspring from a cross with Malverina still consists of more than fifty genotypes. Population is kept in greenhouse and several genotypes of them are already planted in the field. The second population (GV x Seyval blanc) was already diminished by several rounds of selection due to incidence of symptoms from mildew and other, mainly fungal diseases. All twenty genotypes are already under field observation and wine evaluation. Observation of the genotypes was performed using OIV descriptors for ampelographical or viticultural traits [16]. As far as it was possible we prepared wine 
Table 1. SSR markers used to characterize both GV derived populations.

\begin{tabular}{|c|c|c|}
\hline Chromosome & Major SSR marker & Minor marker \\
\hline 1 & $\begin{array}{l}\text { Vrzag29, UCH19, VMC4d2, } \\
\text { VMC3g9 }\end{array}$ & $\mathrm{UCH} 29, \mathrm{Scu} 4$ \\
\hline 2 & $\begin{array}{l}\text { VVIo55, Vrzag93, VVIB01, } \\
\text { ISV3, VMC3b10 }\end{array}$ & VVIB23 \\
\hline 3 & VVMD28, VMC1g7 & VMC4c8, VMC2e9 \\
\hline 4 & $\begin{array}{l}\text { VVMD32, VVIP77, } \\
\text { VMC7h3, Vrzag21, Vrzag82, } \\
\text { VVIT30, VMC6g10 }\end{array}$ & \\
\hline 5 & $\begin{array}{l}\text { VVMD27, VVIN40, } \\
\text { VMC3b9, VMC5e11, }\end{array}$ & $\begin{array}{l}\text { Vrzag79, VVIN33, } \\
\text { VMC6e10 }\end{array}$ \\
\hline 6 & $\begin{array}{l}\text { VMC2g2, VMC4h5, } \\
\text { VMC4g6, VMC } 2 \mathrm{~h} 9\end{array}$ & \\
\hline 7 & $\begin{array}{l}\text { VVMD7, VVMD31, } \\
\text { Vrzag62, VVIP75, VMC5h5, } \\
\text { VMC5e2.2, VMC8d11, } \\
\text { VMC16f3 }\end{array}$ & \\
\hline 8 & $\begin{array}{l}\text { VVS4, VMC1e, VMC5g6.1, } \\
\text { VMC1b11, VMC2h10, } \\
\text { VMC2f12, VMCNG2e2, } \\
\text { VMC4d3 }\end{array}$ & \\
\hline 9 & VMC2d9, VMC2e2, VMC3h5 & VMC1c10 \\
\hline 10 & $\begin{array}{l}\text { Vrzag64, Vrzag67, VRG1, } \\
\text { VMC2e8, VMC2a10 }\end{array}$ & Vrzag25, \\
\hline 11 & VVMD8, VVIV35 & $\begin{array}{lr}\text { VVMD25, } & \\
\text { VVIP36A, } & \text { UDV17, } \\
\text { UDV48, } & \text { A005, } \\
\text { VMC6c3 } & \end{array}$ \\
\hline 12 & $\begin{array}{l}\text { Scu5, VMC2h4, VMC4h2, } \\
\text { VMC4a9, VMC } 8 \mathrm{~g} 9\end{array}$ & $\begin{array}{l}\text { VMC1g3.2, } \\
\text { VMC5c6, } \\
\text { VMC4f3.1, }\end{array}$ \\
\hline 13 & $\begin{array}{l}\text { VVS1, VMC9h4.2, VMC2a3, } \\
\text { VMC } 3 \mathrm{~d} 8, \text { VMC5g11, } \\
\text { VMC3e5, }\end{array}$ & VMC8e6 \\
\hline 14 & $\begin{array}{l}\text { Vrzag112, VVIP05, } \\
\text { VMC2e3, VMC6e1, }\end{array}$ & $\begin{array}{l}\text { VRG9, VMC2b11, } \\
\text { VMC2c3, }\end{array}$ \\
\hline 15 & $\begin{array}{l}\text { VVMD30, VVIV67, } \\
\text { VMC5g8, VMC4d9.2, }\end{array}$ & \\
\hline 16 & $\begin{array}{l}\text { VVMD5, SCU14, VVIV17, } \\
\text { VMC4b7.2, VMC5a10 }\end{array}$ & \\
\hline 17 & $\begin{array}{l}\text { VVIq22b, VMC2h3, } \\
\text { VMC3a9, VMC3c11.1, }\end{array}$ & $\begin{array}{lr}\text { Scu6, } & \text { VVIB09, } \\
\text { VVIP47b, } & \text { VVIS63, } \\
\text { VVIV08, } & \text { VVIP44, } \\
\text { UDV103, } & \text { VMC9g4 }\end{array}$ \\
\hline 18 & $\begin{array}{l}\text { VVIN16, VMC2b1.1, } \\
\text { VMC6f11, VMC8f4, } \\
\text { VMCNG1b9, }\end{array}$ & VVIP8, VMC7f2 \\
\hline 19 & $\begin{array}{l}\text { VVIV70, VVIP17A, } \\
\text { VMC9a2.1, VMC3B7.2, } \\
\text { VMC6c7, VMC7B1, } \\
\text { vMC5H11, }\end{array}$ & \\
\hline
\end{tabular}

from all single genotypes of the population and performed sensorial evaluations as well as analytical analyses. One of the goals was to select vines within the off spring with similar wine aroma as known from the parental variety Grüner Veltliner. For that reason we measured the content of Rotundone, a terpene with high relevance for the varietal typicity. Rotundone was measured with
Table 2. Definition of allele segregation within population 1929 at the chromosome 10.

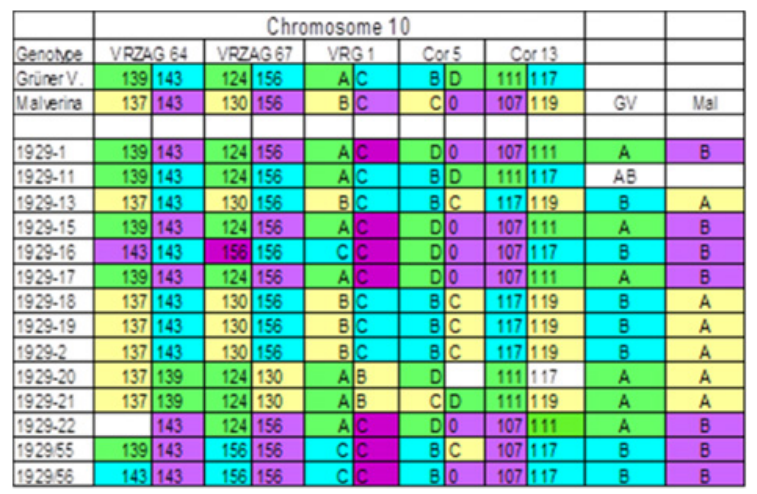

GC-MS equipment and the samples had to become enriched by concentrating the original wine [14].

Segregation pattern was investigated by applying 290 SSR markers. Not all of them proliferated appropriate allelic fragments. Due to distortions in the segregation only a limited number of the markers were involved in the chromosome definition.

SSR markers (Table 1) were developed as mentioned before [17] (Mandl et al., 2007). They were either detected by automatic fluorescence sequencer or by manual silver staining. In the case of silver staining the exact sizing was neglected. Furthermore the task was to attribute the alleles to one of the parental origin. Statistical calculations were done by using SSPS program.

\section{Results and discussion}

About 290 SSR markers were applied to study the segregation behavior within the populations. 195 resulted in polymorphic alleles with segregation in the off spring. Finally, 92 markers were involved in the definition of the chromosomal inheritance. That means, on average 5 markers are sufficient to recognize which of the chromosomes are inherited. Each seedling of both populations was characterized by the presented SSR markers (Table 1). Therefore we could reconstruct consistence of alleles and finally inheritance of the chromosomes. Thus we gained knowledge about inheritance of single chromosomes due to their behavior within the population (Table 2). Some of them were not transferred to the next generation and few of them were sensitive to mutations and showed skewed segregation.

Markers with linkage to known traits were investigated and assessed for their relevance in the genotype. Correlation of chromosomes with ampelographic descriptors according to the OIV definition could be calculated as demonstrated in Table 3.

\subsection{Population 1929 (Grüner Veltliner $x$ Malverina)}

The population consisting of 65 seedlings, two of which, however represent selfings. Therefore it could be argued that these vines belong to an early stage population without having done essential selection steps. It was supposed to find each chromosome with a rate of $50 \%$. Compared to the population 1979 (GV x Seyval bl.) it could be observed that alleles from the parents $\mathrm{GV}$ and Malverina show higher similarity tha GV and Seyval blanc. We observed 
Table 3. Correlation of OIV descriptors with the chromosomes of population 1929.

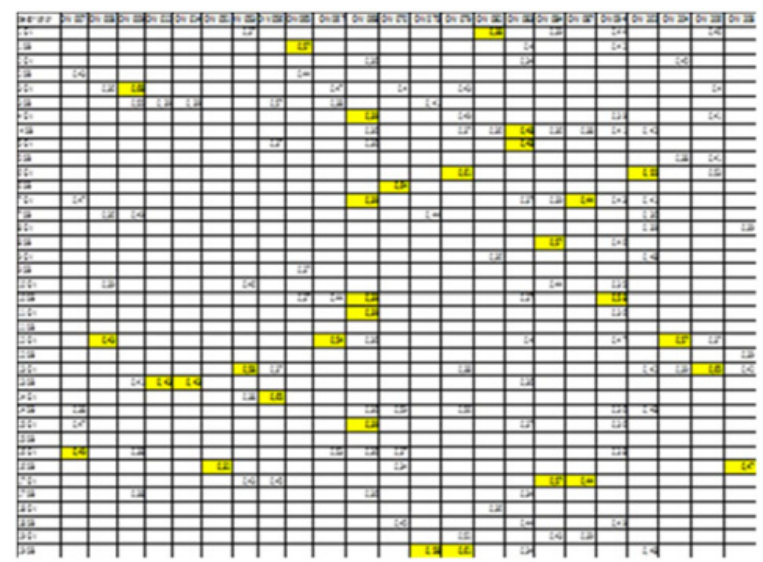

Table 4. Resistance against Powdery mildew according to OIV 456 within population 1929.

\begin{tabular}{|l|c|c|c|}
\hline genotype & Mal. A & Mal. B & OIV 456 \\
\hline $1929-3$ & 1 & 0 & 3 \\
\hline $1929-10$ & 0 & 0 & 3 \\
\hline $1929-15$ & 1 & 0 & 5 \\
\hline $1929-21$ & 1 & 0 & 5 \\
\hline $1929-23$ & 0 & 1 & 7 \\
\hline $1929-27$ & 1 & 0 & 5 \\
\hline $1929-40$ & 0 & 1 & 8 \\
\hline $1929-46$ & 1 & 0 & 4 \\
\hline $1929-49$ & 0 & 1 & 7 \\
\hline $1929-18$ & 1 & 0 & 3 \\
\hline $1929-51$ & 0 & 1 & 8 \\
\hline $1929-52$ & 0 & 1 & 7 \\
\hline $1929-57$ & 1 & 1 & 5 \\
\hline $1929-37$ & 1 & 0 & 5 \\
\hline $1929-43$ & 0 & 1 & 7 \\
\hline $1929-45$ & 1 & 0 & 3 \\
\hline $1929-47$ & 1 & 0 & 7 \\
\hline $1929-38$ & 1 & 0 & 5 \\
\hline $1929-20$ & 1 & 0 & 5 \\
\hline $1929-22$ & 1 & 0 & 3 \\
\hline $1929-25$ & 0 & 1 & 8 \\
\hline $1929-58$ & 1 & 0 & 3 \\
\hline $1929-28$ & 0 & 1 & 7 \\
\hline $1929-31$ & 0 & 1 & 7 \\
\hline $1929-4$ & 0 & 1 & 5 \\
\hline $1929-9$ & 1 & 0 & 5 \\
\hline $1929-39$ & 0 & 1 & 8 \\
\hline & & & \\
\hline
\end{tabular}

less mutations and less skewed segregation in 1929 than in population 1979.

Chromosome $\mathrm{Nr} 1$ is one of the most stable ones and only 4 markers were sufficient to define the inheritance of the chromosomes. Each of the chromosomes appears with the same frequency in the off spring. We could align the ampelographic parameters OIV 2, OIV 55, OIV 65, OIV 73 , OIV 80, OIV 154 to this chromosome (Table 3 ). It was suggested that flowering time and ripening traits are linked to this place [18]. Chromosome 2 is even stable and with 6 SSR markers heritage of chromosomes could be confirmed. OIV 68 is linked to the chromosome and from literature it is known that berry skin color is also coded there [9]. We observed only white berried bunches and could not observe any segregation. Also the region where sex of vine [19] is determined should be located at Chr.2 which we could not verify due to monomorphic hermaphrodite vines. Chromosome 3 could be defined by the use of 4 markers and the distribution is normal. One vine showed distorted segregation due to changes in the combination what could be explained as crossing over. OIV 5, OIV 9, OIV 86 showed linkage to Chr 3. The Chromosome 4 was defined on the base of 7 markers and it seems not as stable as the others. The marker VVIP 77 is not equally distributed and one of the GV alleles could not be found in the population, while the other alleles showed no irregularities. From former mapping it is known that vigor of the shoot [20] or even sensitivity against Plasmopara [11] could be located at that chromosome. OIV 17, 65, 91 and 92 are also associated with chromosome 4. Chromosome 5 reveals to be stable and equally distributed inheritance in our population. It is linked with OIV 4, 53, 83 and 84 [20]. The chromosome 6 indicates stability and could already be defined with 4 markers. The distribution of the alleles shows similar frequencies. OIV 1, 79 and 202 are correlating to this chromosome. There also the accumulation of sugar is said to take place [21]. We could not observe a significant segregation in sugar accumulation independent from the quantity of yield. Number 7 is stable concerning GV alleles but is distorted with alleles of Malverina. It was reported that in this area induction of berry ripening and bud burst are located [18]. Furthermore major $\mathrm{N}$ source for yeast assimilable $\mathrm{N}$ is located there [21]. Chromosome 8 was less stable and more SSR markers were used to define the heritage. Especially some alleles of Malverina are deviating from the segregation pattern. Also, the chromosomes 9 and 10 seem to be inherited in a conserved way without distortion. OIV 53 and 202 correlate with chromosome 10. For Malverina the definition of chromosome 11 failed due to homozygous alleles. In the same group the QTL for Mg uptake was detected [17].

With 6 markers the chromosome 12 was defined and the stability confirmed. OIV 8, 67 and 204 correlate with alleles while in some genotypes linkage to Plasmopara resistance was located as Rpv 6 and 13. Chromosome 13 contains regions responsible for OIV 12, 14, 53, 206 and even in some maps resistance against powdery mildew [22]. Hence the stability of the alleles was not as high as in other chromosomes. The situation with chromosome 14, where OIV 56, 70, 71 and 79 are associated, appeared to be similar.

Chr. 15 seems stable and is linked with traits of OIV $7,54,86$ as well as resistance to powdery mildew in Ren 3 [11]. The marker for Ren3 VVIV67 allows to recognize the source of resistance and could be aligned to the trait within population 1929 (Table 4). In group 16 stability of Malverina alleles was not perfect. Association with OIV 7 and 208 could be recognized. It was mentioned that this chromosome is linked to time of maturing [24]. Also markers associated to ethylene production could be detected [25]. Within chr. 17 we could observe a perfect segregation of GV alleles but failed to find polymorphic Malverina alleles. We concluded that Malverina is at chr. 17 homozygous. OIV 84 and 87 are correlating with the same region in the genome. In former studies OIV 3, 9 and 85 was aligned [21]. For Chromosome 18 the segregation of alleles could easily be defined with five SSR markers. 
Table 5. Content of Rotundone in wine of the population 1979.

\begin{tabular}{|l|r|}
\hline Grüner Veltliner & 35,9 \\
\hline Seyval blanc & 14,98 \\
\hline $1979 / 10 / 1 / 24$ & 17,63 \\
\hline $1979 / 10 / 1 / 29$ & 11,34 \\
\hline $1979 / 10 / 2 / 13$ & 11,66 \\
\hline $1979 / 10 / 2 / 22$ & 11,58 \\
\hline $1979 / 10 / 3 / 13$ & 14,85 \\
\hline $1979 / 10 / 3 / 26$ & 20,6 \\
\hline $1979 / 10 / 3 / 26$ & 20,6 \\
\hline $1979 / 10 / 3 / 29$ & 20,6 \\
\hline $1979 / 10 / 3 / 33$ & 12,52 \\
\hline $1979 / 10 / 3 / 33$ & 12,52 \\
\hline $1979 / 9 / 1 / 66$ & 9,56 \\
\hline $1979 / 9 / 1 / 68$ & 21,27 \\
\hline $1979 / 9 / 1 / 68$ & 21,27 \\
\hline $1979 / 9 / 1 / 81$ & 12,75 \\
\hline $1979 / 9 / 1 / 82$ & 11,18 \\
\hline $1979 / 9 / 1 / 86$ & 12,27 \\
\hline $1979 / 9 / 2 / 79$ & 13,38 \\
\hline $1979 / 9 / 2 / 83$ & 20,5 \\
\hline $1979 / 9 / 2 / 83$ & 20,5 \\
\hline $1979 D$ & 13,25 \\
\hline $1979 E$ & 14,33 \\
\hline $1979 F$ & 13,95 \\
\hline $1979 G$ & 19,42 \\
\hline $1979 / 1$ & 20,64 \\
\hline
\end{tabular}

We only find relevance for OIV 94 but other papers show influence in berry weight or size [23] and dependance on the population resistance against Plasmopara [11] or Erysiphe [26].

Chr. 19 was less stable than others and seven SSR markers were needed to follow segregation. Especially the GV alleles showed distortions. OIV descriptors 75 and 79 showed correlation while OIV 87 was aligned in another population $[11,21]$. In this region the quantity of the crop is determined. Correlations were calculated according to the method of Pearson at the $\mathrm{p}<0,01$ level.

\subsection{Population 1979 (Grüner Veltliner x Seyval blanc)}

Only 24 genotypes were involved in the analysis of a formerly huge population. These genotypes have survived several rounds of selections. The vines are kept outside in the field for viticultural observations and even for wine evaluations. Genotypes with reduced vitality or sensitivity to fungal diseases were already eliminated. That means 1979 offered no random distribution of chromosomes. The stability of the chromosomes was lower than in population 1929 maybe due to a higher degree of different alleles. Despite the higher resistance in the field the genetic base showed more distortion and skewed segregation. Similar as in 1929 there was total absence of one of the chromosomes designated as number 4 of $\mathrm{GV}$. Chr 11 is less stable concerning the alleles of Seyval blanc. Chr 15. of the seedlings contains only monomorphic loci despite heterozygous origin of Seyval blanc. Due to the association with resistance to Powdery mildew the better chromosome was the one with shorter allele length and only genotypes carrying this allele could convince in the selection process. The marker VVIV 67 let us conclude that in all genotypes of population 1979 Ren3 is present. Nevertheless differences in sensitivity against Powdery mildew could be observed under viticultural conditions. At the chr. 19 skewed segregation of Seyval alleles inhibited a precise definition of chromosome within the off spring.

Nevertheless we gained enough data and also information from analysis of 1929 contributed to consideration in the decision to keep a single genotype.
Table 6. Inheritance of the GV chromosomes to the offspring Donauveltliner in consideration of their origin (dark green= Rebe St. Georgen, bright green=Traminer).

\begin{tabular}{|c|c|c|c|c|c|c|c|}
\hline \multicolumn{8}{|c|}{ Donzuveltiner } \\
\hline Morker & Chromos om of & \multicolumn{2}{|c|}{ Gr.vertine } & \multicolumn{2}{|c|}{ Div } & \multicolumn{2}{|c|}{ sowal bans } \\
\hline $\operatorname{van} 2 x$ & 1 & 114 & 116 & 114 & 122 & 118 & 122 \\
\hline VMC:D10 & 2 & $B$ & D & A & $D$ & $A$ & $c$ \\
\hline VMc:iq & 3 & 250 & 262 & 218 & 250 & 218 & 248 \\
\hline VYMOs & 4 & 238 & 254 & 248 & 254 & 248 & 270 \\
\hline vnason & 5 & 242 & 246 & 242 & 256 & 256 & 258 \\
\hline VMC $2 p^{2}$ & 6 & 122 & 124 & 124 & 130 & 128 & 130 \\
\hline WVMo? & 7 & 245 & 255 & 235 & 255 & 235 & 241 \\
\hline Vic ies & 8 & 209 & 229 & 225 & 229 & 223 & 225 \\
\hline vac ans & 9 & A & $B$ & A & $E$ & $D$ & $E$ \\
\hline$v_{n a 2} 60$ & 10 & 124 & 156 & 156 & 164 & 136 & 164 \\
\hline UOV 013 & 11 & c & $E$ & $B$ & c & A & 8 \\
\hline vMc $8 p$ & 12 & 175 & 185 & 183 & 185 & 167 & 183 \\
\hline vinc $3 d s$ & 13 & $c$ & $E$ & A & $E$ & $A$ & $D$ \\
\hline $\operatorname{van} ; 112$ & 14 & 232 & 240 & 236 & 240 & 228 & 236 \\
\hline WVN G & 15 & c & $D$ & $B$ & c & A & $B$ \\
\hline WWN 17 & 16 & c & $D$ & $B$ & c & $B$ & $E$ \\
\hline VMc $3 n$ & 17 & A & D & c & $D$ & $B$ & $c$ \\
\hline VMCNG Da & 18 & 148 & 156 & 152 & 156 & 152 & 160 \\
\hline vic 607 & 19 & 151 & 157 & 101 & 151 & 101 & 169 \\
\hline
\end{tabular}

It is also feasible to follow back the chromosome to the grand parents or to the non-vinifera origin [13]. Nowadays defined chromosomes will not replace the selection or evaluation process but assists to make the right decision about a promising genotype.

\subsection{Rotundone analysis}

The Rotundone content of Grüner Veltliner wines is lies between 20 and $50 \mathrm{ng} / \mathrm{l}$ and in our reference sample it was about $35 \mathrm{ng} / \mathrm{l}$, while wine of Seyval blanc only could reach half the value. None of the seedling shows higher content of Rotundone than Grüner Veltliner. Only one offspring of the 1929 population could reach a similar value as GV. Segregation analysis of wines from 1929 reveals correlation mainly with chromosome 5 . This is no surprise as the chromosome 5 was identified as the place in the genome where the terpenes are coded [12]. What was more surprising is the fact that Seyval blanc chromosome 9 is significantly linked to the Rotundone content. Correlation was calculated based on the method of Pearson with significance at the $\mathrm{p}<0.01$ level. Therefore it seems that the contribution for Rotundone consists of a constant part from Grüner Veltliner chromosome 5 and a segregating part from Seyval blanc chr. 9. Values below the Seyval content could be explained due to the segregation of two alleles with different levels of Rotundone formation (Table 5).

\subsection{Final selection}

In the case of the traditional variety Grüner Veltliner we already have defined the heritage from a cross of St. Georgen x Traminer [5]. While Traminer is one of the key donor varieties for quality development under historic aspects we intended to select seedlings with high percentage of Traminer chromosomes. Finally we chose one of the seedlings of (Grüner Veltliner x Seyval blanc) for high stability and resistance to diseases mainly derived from Seyval blanc and high wine quality brought in by grandparent variety Traminer. In the meanwhile the variety was named Donauveltliner and is proposed for classification in Lower Austria and is already classified in Burgenland, with other regions still following. It is 
known that Traminer has higher sugar accumulation rate than most other varieties and even Donauveltliner shows this behavior inherited from Traminer. Sugar values of the must are consistently higher than observed in the parent GV. Donauveltliner is predominantely influenced by the Traminer chromosomes (table 6), especially the chromosomes 5 and 8 which are both responsible for the production of terpenes derived from the aromatic The decision for this genotype was taken due to the higher wine quality as compared to wines derived from other seedlings of the same population. The loose structure of the grape and the small berries reinforced the very satisfying viticultural performance. Donauveltliner has shown agreeable stability in the field without reduced spraying and is favored for organic production.

\section{References}

[1] A. Calonnec, S. Wiedemann-Merdinoglu, L. Deliere, P. Cartolaro, C. Schneider, F. Delmotte Plant Pathol. 62, 533-544 (2013)

[2] www.austrianwine.com

[3] D. Bellin, E. Peressotti, D. Merdinoglu, S. Wiedemann-Merdinoglu, A.F. Adam-Blondon, G. Cipriani, M. Morgante, R. Testolin, G. Di Gaspero, Theor. Appl. Genet. 120, 163-176 (2009)

[4] F. Regner, R. Hack, K. Hanak, J.-L. Santiago Acta Horticulurae 827, 245-251 (2006)

[5] F. Regner, R. Hack Mitteilungen Klbg. 59, 199-208 (2009)

[6] B.M. Fischer, I. Salakhutdinov, M. Akkurt, R. Eibach, J. Edwards, R. Töpfer, E. Zyprian, Theor. Appl. Genet. 108, 501-515 (2004)

[7] S. Myles, S.Mahanil, J.Harriman, K.M. Gardner, J.L. Franklin, B. Reisch, D.W. Ramming, C.L. Owens, L. Li, E.S. Buckler, L. Cadle-Davidson Molecular Breeding 35, 88 (2015)

[8] E. Herzog , R. Töpfer, L. Hausmann, R. Eibach, M. Frisch Vitis 52 (4), 193-196 (2013)

[9] A.F. Adam-Blondon, C. Rouz, D. Claux, G. Butterlin, D. Merdinoglu, P. This, Theor. Appl. Genet. 109, 1017-1027 (2004)

[10] M. Salmaso, G.Malacarne, M.Troggio, G. Faes, M.Stefanini, M.S.Grando, R.Velasco, Theor. Appl. Genet. 116(8), 1129-1143 (2008)
[11] L.J. Welter, N. Göktürk-Baydar, M. Akkurt, E. Maul, R. Eibach, R. Töpfer, E. Zyprian, Molecular Breeding 20(4), 359-374 (2007)

[12] J. Battilana, F. Emanuelli, G.Gambino, I. Gribaudo, F. Gasperi, P.K. Boss, M.S. Grando, Journal of Exper. Bot. 62(15), 5497-5508 (2011)

[13] T. Siebert, C.Wood, G. Elsey, A.P. Pollnitz 2008 J. Agric. Food Chemistry 56 (10), 3745-3748 (2008)

[14] L. Caputi, S. Carlin, I. Ghiglieno, M. Stefanini, L. Valenti, U. Vrhovsek, F, Mattivi J. Agric. Food Chemistry59 (10), 5565-5571 (2011)

[15] M.S.Grando, D.Bellin, K.J.Edwards, C.Pozzi, M. Stefanini, R. Velasco Theor. Appl. Genet.106, 1213-1224 (2003)

[16] OIV, Office International de la Vigne et du Vin, $2^{\text {nd }}$ Edition of the OIV descriptor list for grape varieties and Vitis species (2001)

[17] K. Mandl, J. Santiago, R. Hack, A. Fardossi, F.Regner Euphytica 149, 133-144 (2006)

[18] I. Fechter, L. Hausmann, E. Zyprian, M. Daum, D. Holtgräwe, B.Weisshaar, R. Töpfer, Theor. Appl. Genet. 127, 1857-1872 (2014)

[19] J. Battilana, S. Lorenzi, F. M. Moreira, P.-MorenoSanz, O. Failla, F. Emanuelli, M.S. Grando Mol Biotechnol 54(3), 1031-1037 (2013)

[20] J.L. Santiago, K. Mandl, R. Hack, F. Regner. Acta Horticulturae 827, 341-346 (2006)

[21] S. Yang1, J.F. Ramírez, Q. Sun, D.C. Manns, G.L. Sacks, A.K. Mansfield, J.J. Luby, J.P. Londo, B.I. Reisch, L.E. Cadle-Davidson, A.Y. Fennel doi.org/10.1371/journal.pone.0149560 (2016)

[22] S. Hoffmann, G. Di Gaspero, L. Kovacs, S. Howard, E. Kiss, Z. Galbacs, R. Testolin. P. Kozma, Theor. Appl. Genet. 116, 427-438

[23] J.A. Cabezas, M.T. Cervera, L. Ruiz-García, J. Carreño, J.M. Martínez-Zapater Genome 49 (12), 1572-1585 (2006)

[24] L. Costantini, J. Battilana, F. Lamaj, G. Fanizza, M.S. Grando, BMC Plant Biology, 8, 38. doi.org/10.1186/1471-2229-8-38 (2008)

[25] F. Licausi, F.M. Giorgi, S. Zenoni, F. Osti, M. Pezzotti, P. Perata, BMC Genomics 11: 719, doi: 10.1186/1471-2164-11-719 (2010)

[26] S. Riaz, A.C. Tenscher, D.W. Ramming, M.A. Walker Theor. Applied Genet. 122(6), 1059-1073 (2011) 